\title{
Análise Crítica do Discurso e a representação do sujeito em situação de rua na Orla Ferroviária de Campo Grande, MS, em textos de noticiários locais
}

\section{Critical Discourse Analysis and the representation of people experiencing homelessness on the Railway Edge of Campo Grande, MS, in local news texts}

Análisis Crítico del Discurso y la representación del sujeto en situación de calle en el Orilla del Ferrocarril de Campo Grande, MS, en los textos de las noticias locales

Guilherme Oliveira Rocha Vicente ${ }^{1}$ Daniele Machado Domingues ${ }^{2}$ Mariana Cavalcante de Brito $^{3}$ Maria Augusta de Castilho ${ }^{4}$

${ }^{1}$ Mestrando em Desenvolvimento Local na Universidade Católica Dom Bosco (UCDB). Graduado em Licenciatura em História pela UCDB. E-mail: guilherme.orv@gmail.com, ORCID: https://orcid.org/0000-0002-0837-1880

${ }^{2}$ Mestranda em Desenvolvimento Local na Universidade Católica Dom Bosco (UCDB). Formada em História pela UCDB. E-mail: danimd91@gmail.com, ORCID: https://orcid.org/0000-0002-3571-5693

${ }^{3}$ Mestranda em Desenvolvimento Local na Universidade Católica Dom Bosco (UCDB). Especialista em Dança e Consciência Corporal pelo Instituto de Educação e Pesquisa Alfredo Torres (IEPAT). Graduada em Educação Física pela Universidade

Federal de Mato Grosso do Sul (UFMS). E-mail: maricbritoufms@gmail.com, ORCID: https://orcid.org/0000-0002-7473-562X

${ }^{4}$ Pós-doutora em Linguística e doutora em Ciências Sociais - História do Brasil, ambas pela Universidade de São Paulo (USP). Professora no Curso de História e no Mestrado em Desenvolvimento Local da Universidade Católica Dom Bosco (UCDB), sendo também responsável pelo Laboratório de História. E-mail: maugusta@ucdb.br, ORCID: https://orcid.org/0000-0001-5235-3164 
Resumo: O presente estudo objetivou examinar como o discurso presente nos noticiários locais de Campo Grande, MS, representam a imagem da população em situação de rua, que circulam na Orla Ferroviária, sob a ótica da Análise Crítica do Discurso. A natureza da pesquisa é bibliográfica com revisão em livros, jornais, revistas, artigos, teses e dissertações; quanto ao tipo do estudo optou-se pelo exploratório, com uma abordagem é qualitativa. O método foi o analítico, com enfoque na Análise Crítica do Discurso (ACD), com base no teórico Holandês Van Dijk (2001). Os resultados apontam que nos três jornais analisados, as matérias são escritas a partir do ponto de vista dos comerciantes e dos moradores da região, excluindo em seu discurso os sujeitos em situação de rua, contribuindo para a manutenção de uma estrutura de poder hegemônica, que tendem a exclusão e no fortalecimento da imagem pejorativa da pessoa em situação de rua.

Palavras-chave: Análise Crítica do Discurso; pessoas em situação de rua; Orla Ferroviária.

Abstract: This study aimed to examine how the discourse present in the local news in Campo Grande, MS, represents the image of people experiencing homelessness that circulate on the Orla Ferroviária (Railroad Edge), from the perspective of Critical Discourse Analysis. The nature of the research is bibliographic with revision in books, newspapers, magazines, articles, theses, and dissertations; as for the type of study, we opted for the exploratory, with a qualitative approach. The method was the analytical one, with a focus on Critical Discourse Analysis (ACD), based on the Dutch theorist Van Dijk (2001). The results point out that in the three newspapers analyzed, the articles are written from the point of view of the merchants and the residents of the region, excluding in their discourse the people experiencing homelessness, contributing to the maintenance of a hegemonic power structure, which tend to exclusion and in the strengthening of the pejorative image of the people experiencing homelessness.

Keywords: Critical Discourse Analysis; people experiencing homelessness; Railroad Edge.

Resumen: Este estudio tuvo como objetivo examinar cómo el discurso presente en las noticias locales en Campo Grande, MS, representan la imagen de la población en situación de calle, que circulan en el Orla Ferroviária (Orilla del Ferrocarril), desde la perspectiva del Análisis Crítico del Discurso. La naturaleza de la investigación es bibliográfica, con revisión en libros, periódicos, revistas, artículos, tesis y disertaciones; en cuanto al tipo de estudio, optamos por el exploratorio, con un enfoque cualitativo. El método fue el analítico, con énfasis en el Análisis Crítico del Discurso (ACD), basado en el teórico holandés Van Dijk (2001). Los resultados señalan que, en los tres periódicos analizados, los artículos están escritos desde el punto de vista de los comerciantes y los residentes de la región, excluyendo en su discurso a los sujetos en situación de calle, contribuyendo al mantenimiento de una estructura de poder hegemónica, que tiende a la exclusión y en el fortalecimiento de la imagen peyorativa de la persona en situación de calle.

Palabras clave: Análisis Crítico del Discurso; gente en situación de calle; Orilla del Ferrocarri 


\section{INTRODUÇÃO}

A representação da população em situação de rua está marcada por uma série de fatores que refletem na visão construída destes indivíduos, em que, aparentemente, a sociedade tende a visualizar de forma análoga o sujeito em situação de rua com dependência química, sujeira e violência. As relações de construção dessa imagem perpassam pela construção discursiva, que tende a trazer a visão de um grupo hegemônico em detrimento a essa população.

Os motivos que impelem a entrada desses sujeitos a essa situação são diversos, podendo ser problemas familiares, abandono parental, migrações, entre outros. Vale salientar que cada indivíduo carrega sua trajetória e suas especificidades, que o levam a enxergar a rua como sua única opção de subsistência.

Este estudo objetivou apresentar como se revela a representação da pessoa em situação de rua da Orla Ferroviária de Campo Grande, MS, na formação discursiva existente nos noticiários locais que abordam o contexto desses sujeitos na Orla .

A natureza da pesquisa é bibliográfica, com revisão em livros, jornais, revistas, artigos, teses e dissertações; quanto ao tipo, é exploratório, com uma abordagem qualitativa.

O método voltou-se ao analítico, com enfoque na Análise Crítica do Discurso (ACD), com base no teórico holandês Van Dijk (2001), ótica que orientou a análise das matérias jornalísticas.

Buscaram-se notícias sobre a situação da Orla e da pessoa em situação de rua, nos acervos on-line dos sites de notícias: Campo Grande News, Correio do Estado e Midiamax, de janeiro de 2018 a maio de 2019, utilizando como palavras-chave nos guias de busca: "Orla Ferroviária”, "morador de rua" (Termo popular e mais frequente nos noticiários) e "pessoas em situação de rua". Foram encontrados um total de 281 matérias nos três jornais, referente ao tema pesquisado, sendo estas divididas por jornais e palavras-chave, como pode ser observado no quadro 1 (relação dos jornais), a seguir: 
Quadro 1 - Relação dos jornais

\begin{tabular}{|l|c|c|c|c|}
\hline \multicolumn{1}{|c|}{ Jornais } & $\begin{array}{c}\text { Total de } \\
\text { matérias } \\
\text { encontradas }\end{array}$ & $\begin{array}{c}\text { Palavra- } \\
\text { chave: "Orla } \\
\text { Ferroviária" }\end{array}$ & $\begin{array}{c}\text { Palavra-chave: } \\
\text { "morador de } \\
\text { rua" }\end{array}$ & $\begin{array}{c}\text { Palavra-chave: } \\
\text { "pessoas em } \\
\text { situação de rua" }\end{array}$ \\
\hline $\begin{array}{l}\text { Campo } \\
\text { Grande News }\end{array}$ & 204 matérias & 60 matérias & 115 matérias & 29 matérias \\
\hline $\begin{array}{l}\text { Correio do } \\
\text { Estado }\end{array}$ & 25 matérias & 13 matérias & 9 matérias & 3 matérias \\
\hline Midiamax & 52 matérias & 14 matérias & 20 matérias & 18 matérias \\
\hline & 281 total & 87 total & 144 total & 50 total \\
\hline
\end{tabular}

Fonte: Campo Grande News, Midiamax e Correio do Estado (2020). Adaptação própria.

Das matérias encontradas, foram escolhidas seis, devido a sua maior aproximação com os dois temas em debate, Orla Ferroviária e população em situação de rua, tendo como títulos: "Na vizinhança de local de assassinato, insegurança é cotidiana"; "Com sorriso de Manoel de Barros ao lado, vagão tem sarau e noite de caldos"; "Caminhada pelo Centro revela espaços que precisam de um olhar humano"; "Enquanto projetos fracassam, Orla Ferroviária é cenário de insegurança"; "Cansados da criminalidade, vizinhos pedem retirada de vagões da Orla Ferroviária"; "Depois de polêmica, líder de comerciantes do Centro pede empenho por moradores de rua".

A averiguação das matérias, empregando as categorias de análise, tornou clara a presença dos seguintes assuntos concernentes à população em situação de rua: sujeira, uso de drogas, assistencialismo, frio, abandono, internação compulsória, invasão, entre outros aspectos, que aparecem com maior frequência nos jornais.

A primeira parte da pesquisa buscou explicar sobre a área territorial do estudo e a trajetória do abandono da Orla Ferroviária, bem como se tornou possível ali ser um local de abrigo para pessoas em situação de rua, mesmo que o ambiente se constitua como local insalubre e inviável como abrigo. O segundo tópico discorre sobre as categorias de Análise Crítica do Discurso de Van Dijk e o fechamento destina-se à investigação dos noticiários e como eles abordam as pessoas em situação de rua. 


\section{POPULAÇÃO EM SITUAÇÃO DE RUA NA ORLA FERROVIÁRIA: BREVE CONTEXTUALIZAÇÃO GEOTERRITORIAL E HISTÓRICA}

É delegado de importância explicitar que a região territorial deste estudo se refere à Orla Ferroviária de Campo Grande, MS, que se localiza entre a Avenida Afonso Pena e a Avenida Mato Grosso, paralelamente à Avenida Calógeras. A Orla se inicia ao lado do Edifício Morada dos Baís, terminando em frente à Estação Ferroviária de Campo Grande. Este espaço se orienta como uma das partes de um patrimônio maior, em que se constitui o Complexo Ferroviário de Campo Grande, Mato Grosso do Sul.

O local da pesquisa escolhido para o estudo foi onde as práticas locais reincidem nos últimos anos ao desamparo do poder público, que vê repetidamente propostas de (re)desenvolvimento da Orla, mas que, infelizmente, fracassaram, situação que afeta diretamente moradores, usuários e comerciantes da região assinalada neste trabalho.

A Orla compreende a localidade em que antes corriam as linhas do trem da antiga Estrada de Ferro Noroeste do Brasil (EFNOB), que, ao entrar em desuso a partir do início da retirada dos trilhos em 1996, como apontado por Marques (2014), tomou novos significados, como espaço de lazer para o uso do cidadão campo-grandense. Nas últimas décadas, surgiram diversas iniciativas vindas de atores externos e internos da região, na tentativa da integração deste espaço no cotidiano socioeconômico de Campo Grande; contudo, em sua maioria, as tentativas resultaram no abandono e na inviabilidade dos projetos. Hoje a área encontra-se em más condições de uso, em esquecimento pela população e negligenciada pelo poder público, que prossegue em tentativa de revitalização do espaço. Entre os principais problemas, menciona-se a falta de iluminação, segurança, degradação, incidência de consumo e tráfico de drogas, sendo que este último ultrapassa o limite da área de pesquisa, estendendo-se às demais regiões do centro comercial da cidade.

A Orla Ferroviária também é reconhecida por abrigar, em representativa parcela, pessoas em situação de rua, que trafegam por toda a região central devido à intensidade do comércio e o fluxo de pessoas. Lima, Silva e Marques (2015, p. 3) elucidam que "[...] a presença dos mesmos concentra-se no Polígono Central, pois, há intensa atividade comercial, dada a presença do camelódromo, do Mercado Municipal Antônio Valente (o 
Mercadão) [...]", além de que "[...] A presença dos moradores de rua também é reflexo do intenso fluxo de pessoas, inclusive turistas, devido a presença de museus nas redondezas e da turística Morada dos Baís." Os moradores de rua encontram em meio ao descaso e à circulação frequente de pessoas um possível local de subsistência, mesmo que em condições precárias.

Abordando de forma mais clara, a Orla se qualifica pelo lugar onde os trilhos da NOB passavam na região central de Campo Grande, acrescentando-se em seu trajeto a Orla Morena e a Via Morena, mas o nosso enfoque do trabalho se dá somente na Orla Ferroviária. A área em questão, como já apontado anteriormente, não tem mais trilhos, sendo substituído por um calçadão para melhorar a mobilidade dos pedestres; sua extensão pode ser mais bem compreendida ao se analisar o Mapa 1, onde a Orla se situa sobre a linha pontilhada destacada em amarelo.

Mapa 1 - Localização da Orla Ferroviária de Campo Grande, MS

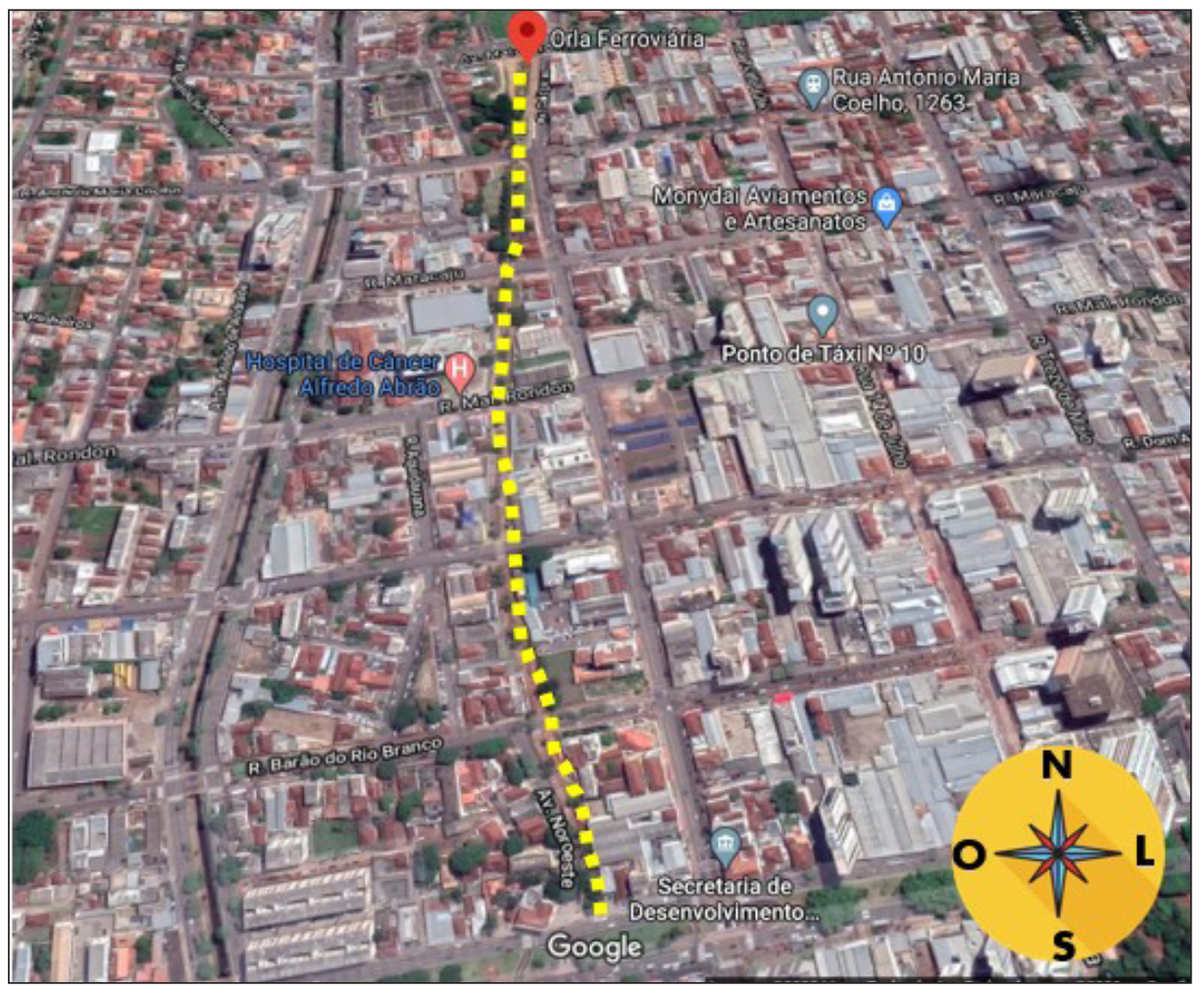

Fonte: Google Maps (2020). Adaptação própria. 
A realidade que levou a Orla Ferroviária a se tornar abrigo para pessoas em situação de rua advém de um processo histórico de desmantelamento do complexo ferroviário, que, em seus mais de 100 anos de existência (1914 a 2020), passou por distintas mudanças em sua conjuntura.

A EFNOB ou NOB se instalou no antigo Estado de Mato Grosso ${ }^{1}$ no início do século XX, no anseio nacional de integração do Brasil com áreas vastas até então desconhecidas e não integradas ao centro econômico da nação brasileira da época, que se concentrava na região Sudeste. A malha férrea teve sua inauguração em 1914 e serviu como ponto importante de desenvolvimento econômico e social da região Centro-Oeste, principalmente no atual Estado do Mato Grosso do Sul e sua capital. Marques (2014 p. 32) esclarece que a chegada da EFNOB foi importante, "pois levou além do desenvolvimento econômico a abertura com os grandes centros nacionais, de forma que trocas culturais também fossem possíveis, colocando a cidade de Campo Grande no cenário nacional como importante centro ferroviário do país".

A Estrada de ferro revela sua importância, quando se observa a formação de vilas e cidades, comércios e hotelarias, assim como o estímulo de diferentes práticas sociais, que surgiram nas áreas de influência da NOB. Ocorreu também o crescimento e estímulo de seus edifícios, cada qual com seu respectivo valor histórico e cultural para a cidade e para o Estado.

No início dos anos 1930 e intensificando-se em 1950, as mudanças no paradigma econômico mundial transformaram as abordagens econômicas em diversas localidades do mundo, incluindo também o Brasil. Marques (2014) aponta que se iniciou nesse período, de forma mais regimentada, um processo de industrialização no país. Um dos setores de maior investimento foi o automobilístico, seguindo a demanda internacional, mas o que interessa ao Estado são as rodovias; estas, a partir de então, começaram a receber maior investimento para o seu desenvolvimento. A predominância do transporte rodoviário ao férreo provocou seu esquecimento gradual, sendo deixado de lado, de forma mais expressiva, no final do século XX e

\footnotetext{
${ }^{1}$ Em 1977, houve a divisão do Estado em duas partes, uma ao norte, Mato Grosso, e uma situada ao Sul, Mato Grosso do Sul.
} 
início do XXI, levando ao significativo desuso, não só a linha férrea, mas também todo um complexo que se formou em seu entorno.

$\mathrm{Na}$ tentativa de salvaguarda desse complexo, que foi de extrema importância para a formação da social e econômica da sociedade sul-mato-grossense, ocorreu o seu tombamento ${ }^{2}$ nas três esferas, Municipal (1996), Estadual (1997) e Federal (2007/2008) ${ }^{3}$, como patrimônio cultural, uma vez que já foi considerado como um dos maiores símbolos do Estado. Surgem, desde então, iniciativas não somente para preservar essas áreas, para que elas não caiam em esquecimento do imaginário social, mas também para que sejam integradas novamente na realidade econômica e cultural de Campo Grande.

Numerosas propostas para a revitalização do trajeto da Orla Ferroviária surgiram nos últimos anos, principalmente por sua proximidade maior com o centro comercial da cidade, onde as possibilidades ampliam-se devido à pungência econômica da região em que está situada. Dentre as alternativas para integração efetiva do local no cotidiano da sociedade da capital, encontram-se a proposta de iluminação, calçadões e viabilização das vias públicas, com o objetivo de transformar o local em um corredor gastronômico e, mais recentemente, com a reforma da rua 14 de Julho, o de realojar vendedores ambulantes para a região.

A Orla Ferroviária perpassou por diversas realidades vividas envolvendo diferentes sujeitos, sejam estes: usuários, comerciantes, empresários, assim como a pessoa que se encontra em situação de rua e que ali se localiza, cada qual com sua realidade experiencial com este local em particular. No caso da pessoa em situação de rua, sua vivência na Orla é marcada pela visão que as externalidades constroem deles, que acabam por atribuir a esse grupo representações relacionadas à violência, roubos, depredação, falta

\footnotetext{
${ }^{2}$ Segundo Santos e Castilho (2016, p. 13) "Tombamento é um instrumento legal de proteção que visa à preservação de um determinado bem ou conjunto de bens culturais. É uma das formas possíveis de preservar os bens do nosso patrimônio cultural."

${ }^{3}$ As três esferas de tombamento podem ser analisadas no documento da PLANURB, sobre o plano urbanístico de uso e ocupação da Orla Ferroviária. Disponível em: http://www.campogrande.ms.gov.br/centro/wp-content/uploads/sites/67/2020/01/20110415160058. pdf. Acesso em: 24 jun. 2020.
} 
de higiene, ao consumo de drogas, entre outros, uma vez que são poucos eventos de comunicação que trazem a população em situação de rua como protagonista de sua própria história.

Resende (2015, p. 111) dialoga sobre a construção imagética dessa população orientando que nossa visão sobre estes advém de construções discursivas, assinalando que: "Isso significa dizer que agimos mediante mecanismos que condicionam e que possibilitam nossas ações potencialmente transformadoras, e que são conformados na atividade daqueles/as que nos antecederam, e de cujos resultados nos apropriamos". Nesse contexto, a visão que carregamos perpassa "[...] a representação discursiva da situação de rua [...] influencia os modos como percebemos e reagimos à vulnerabilidade social, e os modos como identificamos pessoas em situação de rua e nos identificamos em relação a essa situação" (RESENDE, 2015, p. 113).

Para se compreender a construção desses discursos e como eles refletem na realidade desses sujeitos, utilizou-se uma categoria de análise apoiada nos escritos produzidos e estimulados por Teun A. van Dijk e sua ótica sobre Análise Crítica do Discurso, que surge com intencionalidade de compreender como esses discursos propagados pelos diversos eventos de comunicação, como literatura, filmes, propagandas, noticiários e indivíduos, por exemplo, constroem a imagem por meio da voz ativa dos grupos hegemônicos em detrimento de grupos marginalizados, como o caso dos moradores de rua, como será apresentado nos tópicos seguintes.

\section{ANÁLISE DO DISCURSO E AS CATEGORIAS DE ANÁLISE DE VAN DIJK}

Sendo de perspectiva crítica e focando-se em problemas sociais, ao analisar um determinado assunto pelas lentes da Análise Crítica do Discurso (ACD), deve-se, sempre que possível, ocupar-se de questões de dominação ou abuso de poder. Van Dijk (2001) explica que o analista deve considerar as experiências e opiniões dos membros dos grupos menos abastados e ainda oferecer ajuda na luta contra a desigualdade social.

Publicações que são desenvolvidas da conduta de como as pessoas convivem em sociedade não apenas são resultados de episódios grupais momentâneos como também têm consequências sobre elas. 
Van Dijk (2001, p. 2003) considera ainda que:

Em outras palavras, a pesquisa em ACD combina o que talvez, pomposamente, costuma ser chamado de "solidariedade com os oprimidos" com uma atitude de oposição e dissenção contra aqueles que, por meio do texto e da conversação, buscam estabelecer, confirmar ou legitimizar o seu abuso de poder. Diferentemente de outras perspectivas, a ACD não nega, mas assume e defende sua posição social e política. Ou seja, a ACD é tendenciosa - e orgulhosa disso.

Pode-se, assim, declarar que a ACD tem uma interpretação crítica de geração de conhecimento, sendo entendida como um mecanismo de posicionamento, focando nos problemas da sociedade e na função do discurso da realização e reapresentação do abuso de poder.

Busca apropriar-se de uma concepção harmoniosa com os objetivos das minorias sociais abusadas, estando atenta às opiniões e experiências desta população, e ainda mostra uma conduta oposta aos que buscam legitimar sua dominação por meio de abuso de poder, sendo acessível a todos e, em especial, às minorias exploradas.

Van Dijk (2001, p. 234), em seu trabalho sobre ACD, observa a importância de enfatizar a emergência de uma abordagem multidisciplinar, como ele mesmo afirma, que: "[...] a ampla e orientada ação para a resolução de problemas, são ao mesmo tempo, fenômenos cognitivos e sociais". Por isso, faz-se mister a utilização de outras abordagens, como: as culturais, históricas, socioeconômicas, lógicas, filosóficas, para lidar com a complexidade de dilemas abordados pela Análise Crítica do Discurso.

Identifica-se, ainda, que a importância dessa multiplicidade pode enfatizar o triângulo discurso - sociedade - cognição, mas que, na visão de Dijk (2001), pode vir a ser interpretada de forma equivocada; portanto, o autor prefere, em um primeiro momento, explicar minunciosamente, assim como informado no Quadro 2, a seguir 
Quadro 2 - Triângulo Discurso, Cognição e Sociedade

\begin{tabular}{|l|l|l|}
\hline \multicolumn{1}{|c|}{ Discurso } & \multicolumn{1}{c|}{ Cognição } & \multicolumn{1}{c|}{ Sociedade } \\
\hline - Evento Comunicativo & - Pessoal & - Inclusão \\
\hline - Interação Comunicacional & - Social & -Estruturas sociais e políticas \\
\hline - Modalidade escrita da língua & - Crenças & - Grupos \\
\hline - Expressão corporal e facial & - Objetivos & - Movimentos sociais \\
\hline - Diagramação do texto e imagens & - Avaliações & - Instituições \\
\hline & - Emoções & - Processos sociais \\
\hline
\end{tabular}

Fonte: Van Dijk (2001).

O discurso ainda pode ser definido como um componente intangível, que instiga a sociedade e é por ela induzida, na construção de valores sociais, culturais e ideológicos que estão gravados nas formas de conhecimento social e individual.

A cognição é uma dimensão obtida socialmente, todavia aperfeiçoada individualmente. Van Dijk (2001, p. 355) esclarece que a cognição "[...] envolve tanto a pessoal quanto a social, crenças, objetivos, avaliações e emoções e qualquer outra estrutura "mental" ou da "memória", como as representações ou os processos envolvidos no discurso e na interação. ".

Na sociedade, é necessária a inclusão do nível local, que são as interações interpessoais, com o nível global, que são as estruturas políticas e sociais, por exemplo, e podem ser definidas como grupos, relações de grupos, entre outros.

Nesse diapasão, Van Dijk (2001, p. 355) mostra uma possível forma de entender a combinação dessas dimensões de cognição e sociedade de uma forma "definidora da relevância do contexto do discurso", pois a integração dessas dimensões faz com que os dilemas sociais possam ser criticados com peculiaridade.

Torna-se importante destacar as macroestruturas semânticas, que são tópicos que informam o que os discursos querem dizer e utilizam a técnica de sumarização, além de serem derivadas dos significados locais. Van Dijk (2001, p. 359) clarifica que, "Por razões discursivas, cognitivas e sociais, os tópicos do discurso desempenham um papel fundamental na comunicação e interação". 
Van Dijk (2001, p. 360) também especifica que:

Como os tópicos têm um papel importante e uma vez que a análise (macroestrutural) tópica pode ser aplicada, recomendo começar a análise a partir deles. Eles fornecem uma ideia geral do assunto de que o corpus trata, além de controlar muitos outros aspectos do discurso e da análise. Observamos que os sumários são, por definição, a expressão das macroestruturas, assim, podemos- por razões práticassimplesmente listar os tópicos do texto sumarizando-os, um método que pode ser repetido em vários níveis de abstração.

Já os significados locais, conforme Van Dijk (2001, p. 361), “[...] são o resultado da seleção feita pelos usuários nos seus modelos de eventos ou em suas crenças mais gerais, ou seja, as que são socialmente compartilhadas".

Pode-se assinalar que os tópicos do discurso e os significados locais também são importantes, visto que:

Ao mesmo tempo, representam o tipo de informação que, sob o controle dos tópicos globais, influenciam mais diretamente os modelos mentais, e, assim, as opiniões e atitudes dos receptores. Com os tópicos, os significados locais são os mais relembrados e facilmente reproduzidos pelos receptores, e por isso, com consequências sociais (VAN DIJK, 2001, p. 361).

No tópico a seguir será retratada, por meio das categorias de análise, a pessoa em situação de rua na Orla Ferroviária, por intermédio de reportagens e sujeitos históricos, participantes das matérias em noticiários locais.

\section{ANÁLISE DA REPRESENTAÇÃO DOS MORADORES DE RUA NA ORLA FERROVIÁRIA EM TEXTOS DE NOTICIÁRIOS LOCAIS}

As condições das ruas de hoje são um problema social com um perfil global. A pobreza extrema tornou-se o foco de atenção dos campos interdisciplinares, mobilizando diferentes setores da sociedade e conquistando um importante espaço de reflexão no campo do discurso. Estes sobre o protagonista e os direitos humanos foram fortalecidos, porém trouxeram junto o preconceito, geralmente espalhado na mídia convencional, por meio da dialética entre o discurso e a sociedade; assim, tais representações podem criar identidade e legitimar as ações relacionadas à vulnerabilidade social. 
Esse problema não é novo e muito menos isolado, pois faz parte do mundo e das cidades globalizadas. A situação de rua é um problema grave que afeta a vida de milhares de pessoas mundialmente, porém este problema vem sendo banalizado e por vezes apagado em diversos meios de comunicação ou veículos midiáticos, como os jornais analisados neste texto.

Neste sentido é que se faz necessária a discussão e análise da representação das pessoas em situação de rua na cidade de Campo Grande, na região da Orla Ferroviária, a partir dos textos dos noticiários virtuais locais.

Para a análise dos discursos jornalísticos a respeito da representação das pessoas em situação de rua das seis publicações, foram definidos alguns critérios de seleção, a saber: tema, recorte temporal e vozes enunciativas.

Inicialmente, realizou-se um recorte temático. Foram escolhidos textos que, de alguma forma, tinham como tema a população em situação de rua na Orla Ferroviária. Em princípio, todos os textos que abordavam a temática direta ou indiretamente foram selecionados. Em resumo, fez-se um levantamento quantitativo sobre a incidência do tema "moradores de rua" e/ou "pessoas em situação de rua" na Orla Ferroviária, ou termos correlatos nos três jornais digitais: Campo Grande News, Midiamax e Correio do Estado.

Pode-se estabelecer alguns assuntos que apresentam aderência com o tema, como: risco social, revitalização urbana, abandono, violência etc. foram considerados em nosso recorte temático. Como já apontado, após a delimitação do assunto, fez-se um recorte temporal das veiculações do tema, compreendido entre janeiro de 2018 e março de 2019. Além do critério temático, há um recorte geográfico. Somente serão analisadas as matérias que abordam a situação de rua na municipalidade de Campo Grande, na região da Orla Ferroviária.

Foram analisadas seis reportagens de três diferentes veículos de comunicação on-line, com a abordagem da temática central das pessoas em situação de rua. Nas reportagens, as pessoas em situação de rua e os comerciantes locais reclamam do descaso das autoridades e do abandono do local, acarretando um alto índice de violência e do uso de drogas por parte dos andarilhos. Palavras como roubo, violência, uso de drogas, abandono, morador de rua, vagões da orla ferroviária são recorrentes em todas as reportagens e jornais analisados, como se pode ser observado na Figura 1 a seguir: 
Figura 1 - Nuvem de palavras

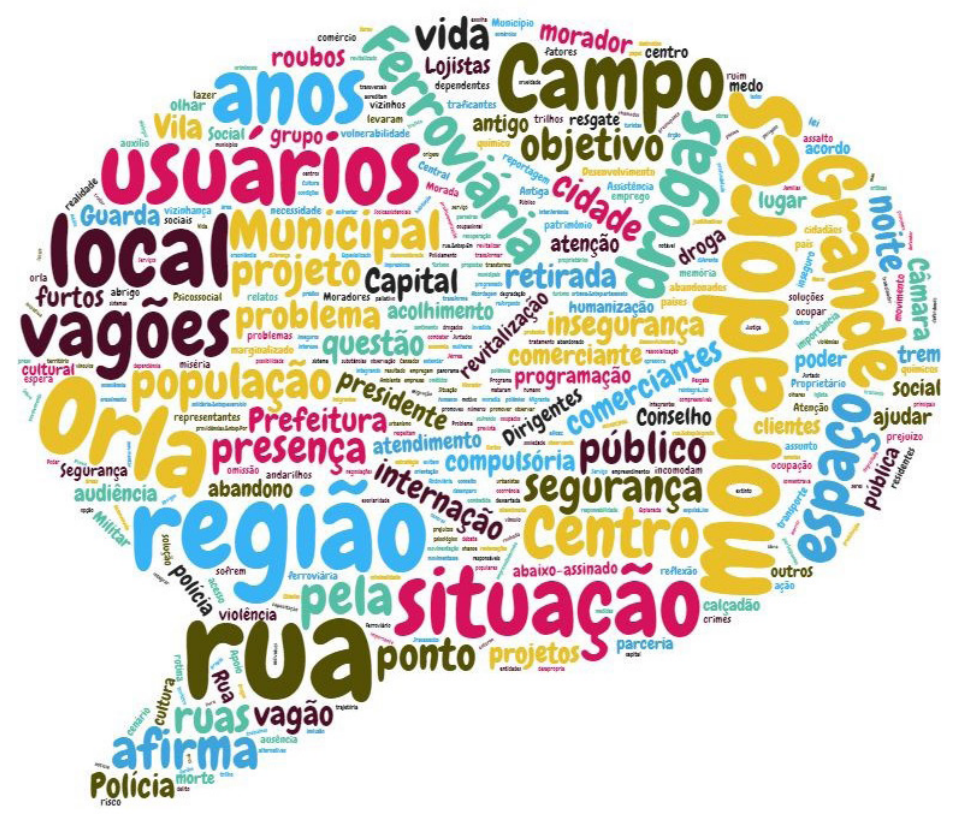

Fonte: Word Cloud, 2020. Adaptação própria.

No título da primeira reportagem analisada, do jornal digital Campo Grande News, pode-se detectar a insegurança da população local, em relação à região e aos moradores em situação de rua.

Na vizinhança de local de assassinato, insegurança é cotidiana

Sede de uma companhia de teatro foi furtada pela sexta vez, no início da manhã de ontem (7), momentos antes da tentativa de assalto que acabou em morte

A tentativa de assalto que terminou na morte do auxiliar de pedreiro Antônio Marcos Rodrigues de Souza, 34 anos, evidenciou um antigo problema enfrentado pelos moradores da Esplanada Ferroviária, ou o "antigo Centro": a violência.

Pelos relatos de quem mora ou trabalha na região, roubos e furtos dividem espaço com inúmeros moradores de rua e usuários de drogas que fazem da Orla Ferroviária moradia (HENRI; RIBEIRO; MACHADO, 2018, s.p.). 
Seguindo, a segunda reportagem do mesmo veículo de comunicação relata a tentativa de resgate cultural de uma comerciante local, trazendo um novo espaço para encontros da população, em uma tentativa de resgate da região.

Com sorriso de Manoel de Barros ao lado, vagão tem sarau e noite de caldos

Intenção é levar cultura a um ponto que há anos é marginalizado e corre o risco de ser extinto em Campo Grande

No Facebook, um evento indicou um novo espaço para música e comidinhas em um dos vagões da Orla Ferroviária. O colorido ganhou nome de "Larica's da Lu" e basta chegar ao local para sentir o batuque de quem encara o microfone aberto e torna diferente 0 clima da região que corre o risco de ser extinta em Campo Grande, por conta do abandono

A intenção dos proprietários é levar cultura e entretenimento a um ponto, que há anos, é marginalizado pela presença de moradores de rua e usuários de droga, explica Luanna Peralta, que ocupou o vagão alugado há três semanas. "Resolvi dar as caras por aqui, porque o que falta para esse lugar é atitude|", diz. (TORRES, 2018a, s.p.).

A terceira, ainda do mesmo jornal, traz ao leitor um olhar mais humanizado ao problema abordado, a questão social e política em relação aos moradores em situação de rua e os vagões abandonados da Orla Ferroviária.

Caminhada pelo Centro revela espaços que precisam de um olhar humano

Não é estranho pensar que as pessoas conhecem tão pouco o meio em que vivem. Basta olhar para o lado para comprovar. Há sempre um porta, janela ou fresta de memória se apagando com o tempo sem que o outro perceba. Foi por isso que um grupo formado por professores e acadêmicos do curso de Arquitetura da UCDB (Universidade Católica Dom Bosco) promoveu um passeio gratuito, para observar e pensar coletivamente sobre a humanização de espaços à mercê do abandono pelo Centro de Campo Grande.

$[\ldots]$

A observação iniciou pela Praça Aquidauana, que nos últimos anos tem lotado com eventos carnavalescos, mas que no restante do ano permanece como ambiente de passagem ou acolhimento para quem 
vive no desamparo sob a miséria ou uso de drogas.

"Uma praça não pode ficar abandonada, isso também enfraquece a utilização do espaço público, ao mesmo tempo, para entender Campo Grande e planejar a cidade temos que levar em conta todos os detalhes, principalmente, essas pessoas que estão aqui no entorno, temos que falar com elas e escutá-las", afirma o professor de Filosofia Josemar Maciel que também organizou o evento a partir do Programa de Desenvolvimento Local da UCDB.

Passos a frente, o grupo se posiciona em um dos vagões da Orla Ferroviária, espaço revitalizado em 2012 com a proposta de levar entretenimento e gastronomia para a região. Mas basta um olhar rápido em volta para saber a quem o local pertence. Com vagões destruídos e abandonados, o local também virou reduto de moradores de rua.

A falta de ligação com quem vive em volta é um dos fatores que contribui para a degradação, aponta o professor de Arquitetura Fernando Camilo. "A vida do território, a vida da vizinhança precisa estar vinculada aos projetos. O urbanista precisa ver a realidade das pessoas a sua volta, nesse caso, as casas não tem contato com a Orla Ferroviário, estão todas de costas para uma área que acaba se tornando um beco" (TORRES, 2018b, s.p.).

A quarta e última reportagem analisada do jornal digital Campo Grande News, salienta novamente em seu título a insegurança em relação à região central da cidade.

Enquanto projetos fracassam, Orla Ferroviária é cenário de insegurança Vagões estão abandonados e viram abrigo para dependentes químicos. Furtos e prejuízo aos comércios são reclamações de moradores.

À espera da retirada pela Prefeitura, os vagões da orla ferroviária, próximo à Praça Aquidauana, tornaram-se abrigos de usuários de drogas e moradores de rua. Moradores e comerciantes da região reclamam do abandono da estrutura e relatam furtos e prejuízos com o aumento da presença dos usuários (GURGEL; SANCHES; KASPARY, 2018).

A quinta reportagem analisada foi do jornal Midiamax e, no título, o autor relata a constante insegurança e violência na região.

Cansados da criminalidade, vizinhos pedem retirada de vagões da Orla Ferroviária 
Fartos de roubos e da insegurança na região da Orla Ferroviária, no centro de Campo Grande, moradores do bairro se juntaram para pedir a retirada dos vagões. Os locais servem de abrigo para moradores de rua que, de acordo com os moradores, são apontados como responsáveis pelos roubos e assaltos nas proximidades.

Fartos de roubos e da insegurança na região da Orla Ferroviária, no centro de Campo Grande, moradores do bairro se juntaram para pedir a retirada dos vagões. Os locais servem de abrigo para moradores de rua que, de acordo com os moradores, são apontados como responsáveis pelos roubos e assaltos nas proximidades (ROCHA, 2018).

A sexta reportagem analisada foi do jornal Correio do Estado, em que o título chama atenção do leitor para a questão social do morador em situação de rua, sendo a única reportagem que propõe uma ressocialização dos moradores em situação de rua e uma "preocupação" com a questão social do problema.

\section{Depois de polêmica, líder de comerciantes do Centro pede empenho por moradores de rua}

Em audiência, ideia de internação compulsória é praticamente descartada

"Chamado à Câmara Municipal menos de um mês depois de lançar polêmico abaixo-assinado que propõe a internação compulsória de moradores da rua, o presidente da Câmara de Dirigentes Lojistas de Campo Grande, Adelaido Luíz Spinosa Vila, parece ter cumprido o objetivo de chamar a atenção para a questão, conforme disse ao Correio do Estado.

Na manhã desta sexta-feira (15), o líder dos comerciantes e ex-presidente do Conselho de Segurança da Região Central foi um dos principais convidados de audiência pública da Comissão Permanente de Saúde da Câmara, onde cobrou dos vereadores e da Prefeitura maior empenho para tratar a questão dos moradores de rua. Em tom mais ameno quando do lançamento do abaixo-assinado.

"Jamais iríamos propor a internação compulsória dos moradores de rua, o que eu gostaria de pedir a todos é que não deixem morrer este assunto, vamos discutir com mais profundidade. A CDL está disponível para ajudar no assistencialismo e profissionalização, auxiliando na busca por um emprego. O que não podemos é ser omisso. Nossa população de rua é refém das drogas, estamos perdendo essas pessoas para o tráfico", disse Vila (RIBEIRO, 2019. s.p.). 
As seis reportagens analisadas, são escritas do ponto de vista dos comerciantes e dos moradores locais. Em nenhuma delas aparece como interlocutor a pessoa em situação de rua ou os dependentes químicos residentes do local. Produz sentidos a partir do ponto de vista do dominante (comerciantes, moradores) e não do dominado (morador de rua); ou seja, sua formação discursiva é de quem defende os interesses de quem está em situação de poder. Por conta dessa inclinação de cunho ideológico, fortalece as enunciações que apresentam o morador de rua associado à marginalidade.

Percebe-se de maneira evidente a força e a manutenção da fala repetida das estruturas de poder e dominação, na avaliação negativa dos grupos marginalizados, em que a falta de responsabilidade do Estado é frequentemente repetida em diferentes tipos de texto, tornando-se parte do pressuposto sobre os quais novos textos são criados.

\section{CONSIDERAÇÕES FINAIS}

Este estudo pretendeu examinar como o discurso presente nos noticiários locais de Campo Grande, MS, representa a imagem da população em situação de rua que circula na Orla Ferroviária, sob a ótica da Análise Crítica do Discurso, utilizando como base seis das 281 reportagens analisadas parcialmente de mídias jornalísticas da cidade.

As transformações que ocorreram na Orla Ferroviária e os consecutivos processos de desmantelamento ocasionaram seu abandono gradual. O esquecimento levou à falta de manutenção e a degradação do espaço. Nesse cenário, o número de pessoas em situação de rua aumentou no local, e estas transitam pela região por enxergarem, nos últimos anos, a Orla como um lugar de subsistência. Portanto, a Orla torna-se local de relação social, envolvendo diferentes indivíduos que se relacionam, vivenciam esse espaço e, em muitos casos, entram em conflito.

Fica evidente, nas matérias, o ponto de vista dos comerciantes e dos moradores locais, todavia em nenhuma delas aparece como interlocutor a pessoa em situação de rua ou os dependentes químicos residentes do local, fortalecendo a cultura local da imagem do morador de rua associado à 
marginalidade. As notícias reincidem na utilização de palavras que remetem à violência, como "insegurança", "roubo", "drogas", trabalhando as notícias sem levar em contexto os motivos que levam a população em situação de rua a transitar e permanecer no local. Constata-se que a escolha de palavras tende a não fazer a devida distinção entre pessoas em situação de rua e dependentes químicos. Formula-se em suas chamadas a ideia de que, em um grupo social diversificado, há apenas "um" grande grupo, relacionado ao uso compulsivo de drogas.

Baseado no que foi demonstrado nesta pesquisa, verifica-se que um dos aspectos mais negativos dessa questão de marginalização e de qualquer forma de representação da realidade estabelecida pelas classes dominantes é a influência de normalizar as situações, razão pela qual é tão complexo mudar essas representações, que terminam por fazer parte dos costumes locais. Portanto, é de fundamental importância para a sociedade o entendimento sobre a Análise Crítica do Discurso (ACD), pois torna possível visualizar e identificar os abusos sofridos pela classe dominada, trazendo à tona a realidade de fatos que, em sua grande maioria, mostram apenas um lado do contexto.

\section{REFERÊNCIAS}

ALMEIDA JUNIOR, Guy Pinto de. Pelas ruas e nas páginas das revistas: estratégias de construção da representação do morador de rua no discurso jornalístico de Ocas e VEJA São Paulo. 2014. 187 p. Dissertação (Mestrado em Comunicação e Práticas de Consumo) - Escola Superior de Propaganda e Marketing, São Paulo, SP, 2014.

GURGEL, Anahi; SANCHES, Izabela; KASPARY, Bruna. Enquanto projetos fracassam, Orla ferroviária é cenário de insegurança: vagões estão abandonados e viram abrigo para dependentes químicos. Furtos e prejuízo aos comércios são reclamações de moradores. Campo Grande News, Campo Grande, MS, 5 set. 2018. Disponível em: https://www.campograndenews.com.br/cidades/capital/enquanto-projetosfracassam-orla-ferroviaria-e-cenario-de-inseguranca. Acesso em: 15 jul. 2020.

HENRI, Guilherme; RIBEIRO, Liniker; MACHADO, Mirian. Na vizinhança de local de assassinato, insegurança é cotidiana: sede de uma companhia de teatro foi furtada pela sexta vez, no início da manhã de ontem (7), momentos antes da tentativa de assalto que acabou em morte. Campo Grande News, Campo Grande, MS, 8 maio 
2018. Disponível em: https://www.campograndenews.com.br/cidades/capital/ na-vizinhanca-de-local-de-assassinato-inseguranca-e-cotidiana. Acesso em: 15 jul. 2020.

LIMA, Antonio Henrique M.; SILVA, João Alberto M.; MARQUES, Heitor Romero. A imagem do morador de rua sob a perspectiva dos comerciantes no polígono central de Campo Grande - Mato Grosso do Sul e suas correlações com o desenvolvimento local em escala humana. Observatorio de la economia Latinoamericana, revista eumed.net, n. 207, fev. 2015.

MARQUES, Helder Gustavo. Memória e transformação urbana: uma análise do patrimônio ferroviário em Campo Grande-MS. 2014. 109 f. Dissertação (Mestrado em Geografia Humana) - Faculdade de Filosofia, Letras e Ciências Humanas, Universidade de São Paulo, SP, 2014.

RESENDE, Viviane de Melo. Não é falta de humanidade, é para dificultar a permanência deles perto de nosso prédio - análise discursiva crítica de uma circular de condomínio acerca de "moradores de rua" em Brasília, Brasil. Discurso e Sociedad, [s.I.], v. 2, p. 422-44, 2008.

RESENDE, Viviane de Melo. Violência simbólica: representação discursiva da extrema pobreza no Brasil - relações entre situação de rua e vizinhança. Discurso e Sociedad, [s.I.], v. 9, n. 1-2, p. 106-28, mar./jun. 2015.

RIBEIRO, Rafael. Depois de polêmica, líder de comerciantes do Centro pede empenho por moradores de rua: em audiência, ideia de intenção compulsória é praticamente descartada. Correio do Estado, Campo Grande, MS, 15 mar. 2019. Disponível em: https://correiodoestado.com.br/cidades/depois-de-polemica-liderde-comerciantes-do-centro-pede-empenho-por/349124/. Acesso em: 15 jul. 2020.

ROCHA, Mylena. Cansados da criminalidade, vizinhos pedem retirada de vagões da Orla Ferroviária: os residentes querem presença da guarda e ações sociais aos usuários de droga. Midiamax, Campo Grande, MS, 11 jun. 2018. Disponível em: https://www.midiamax.com.br/cotidiano/2018/cansados-da-criminalidademoradores-pedem-a-retirada-de-vagoes-da-orla-ferroviaria. Acesso em: 15 jul. 2020.

SANTOS, Maria Christima de L. F; CASTILHO, Maria Augusta. Catálogo: Patrimônio Histórico e Cultural de Mato Grasso do Sul. 1. ed. Campo Grande, MS: Life Editora, 2016. 93 p. 
TORRES, Thailla. Caminhada pelo Centro revela espaços que precisam de um olhar humano. Grande News, Campo Grande, MS, 27 maio 2018b. Disponível em: https:// www.campograndenews.com.br/lado-b/arquitetura-23-08-2011-08/caminhadapelo-centro-revela-espacos-que-precisam-de-um-olhar-humano. Acesso em: 15 jul. 2020.

TORRES, Thailla. Com sorriso de Manoel de Barros ao lado, vagão tem sarau e noite de caldos: intenção é levar cultura a um ponto que há anos é marginalizado e corre o risco de ser extinto em Campo Grande. Campo Grande News, Campo Grande, MS, 24 maio 2018a. Disponível em: https://www.campograndenews.com. br/lado-b/diversao/com-sorriso-de-manoel-de-barros-ao-lado-vagao-tem-saraue-noite-de-caldos. Acesso em: 15 jul. 2020.

VAN DIJK, Teun. A. Análise crítica do discurso multidisciplinar: um apelo a favor da diversidade. Disponível em: http://www.revistas.usp.br/linhadagua/ article/view/65164. Acesso em: 10 jun. 2020. 
